\title{
Rabaska
}

Revue d'ethnologie de l'Amérique française

\section{LOUDER, DEAN, JEAN MORISSET et ÉRIC WADDELL. Vision et visages de la Franco-Amérique. Québec, Septentrion, 2001, 346 p. ISBN 2-89448-300-7}

\section{Normand Beaupré}

Volume 4, 2006

URI : https://id.erudit.org/iderudit/201788ar

DOI : https://doi.org/10.7202/201788ar

Aller au sommaire du numéro

Éditeur(s)

Société québécoise d'ethnologie

ISSN

1703-7433 (imprimé)

1916-7350 (numérique)

Découvrir la revue

Citer ce compte rendu

Beaupré, N. (2006). Compte rendu de [LOUDER, DEAN, JEAN MORISSET et ÉRIC WADDELL. Vision et visages de la Franco-Amérique. Québec, Septentrion, 2001, 346 p. ISBN 2-89448-300-7]. Rabaska, 4, 177-179.

https://doi.org/10.7202/201788ar d'utilisation que vous pouvez consulter en ligne.

https://apropos.erudit.org/fr/usagers/politique-dutilisation/ 
Louder, Dean, Jean Morisset et Éric Waddell. Vision et visages de la Franco-Amérique. Québec, Septentrion, 2001, 346 p. ISBN 2-89448300-7.

Comment rédiger un compte rendu sur les dix-huit chapitres d'une œuvre qui se veut tout au moins inclusive de la francophonie nord-américaine ? Ce n'est pas facile puisqu'il faut soit commenter chaque " histoire » ou en sélectionner quelques-unes pour offrir le plus près possible les idées majeures de l'œuvre entière. J'ai donc opté pour ce deuxième choix.

Premièrement, puisque je suis moi-même franco-américain de la Nouvelle-Angleterre, je me sens tendu entre mon identité d'universitaire et celle de Franco les deux pieds bien ancrés dans ma culture. Il y a donc chez moi un tiraillement entre le côté objectif de l'érudition et le côté subjectif du vécu. Afin de rendre justice aux textes lus et aux auteurs, je dois me mettre en garde contre un excès de subjectivité. Cependant, je me sens obligé par fidélité au partage de la culture francophone d'insérer ici et là quelques observations issues de mes propres expériences.

Comme le dit Zachary Richard au tout début, «nous, les Français d'Amérique, sommes soit en danger de disparaître, ou bien avons déjà disparu ». Voilà le bilan des choses à propos de la Franco-Amérique. Comment vivre son identité francophone dans des milieux où l'assimilation progresse de plus en plus? Alors, la plupart des témoignages de ce livre se concentrent sur la question d'identité et parfois les contraintes de la culture telles que nous le rappellent Waddell et Louder : « La culture (minoritaire) est-elle une prison ou une fenêtre sur le monde ? " Pour sa part, Clark Blaise fait allusion à James Joyce et à son œuvre autobiographique, A Portait Of The Young Man As An Artist, dans laquelle il nous parle de grandir sous les filets de sa propre culture. Ce que Blaise ne mentionne pas, c'est que l'artiste même voulait sauter hors des filets de sa culture qui l'engouffrait. Avec Joyce ce n'est plus le cas de survivre mais de s'éloigner le plus loin possible. 
Avec Michel Bouchard, qui nous parle de la francophonie de l'Ouest canadien, le lecteur suit l'aventure de la famille Lamoureux du Québec à l'Illinois, puis au Kansas, en Californie et aux territoires de l'Orégon avant de s'établir comme colons en Alberta en 1872. Grâce à l'histoire orale qui lui est léguée, l'auteur peut reconstituer les mésaventures des frères Lamoureux, deux prospecteurs, à la poursuite d'un Eldorado. C'est ainsi que Bouchard affirmera : «Ce qui me surprend une fois de plus c'est la grande mobilité de cette population, souvent caractérisée par des liens de parenté ». Voilà un des grands traits de notre histoire en temps que francophones nord-américains: le goût ou le besoin du déplacement que nous reverrons tout le long des autres témoignages.

Une autre grande tendance, c'est la force de l'assimilation qui fait dire à Melinda-Marie Jetté, dans son témoignage sur les Jetté de 1'Orégon, qu' " Après l'assimilation, après le déclin des distinctions ethniques, il reste la mémoire. Pour une famille et moi-même, c'est la mémoire familiale qui nous donne une identité "). Pour sa part, Barry Rodrigue ose parler du stéréotype franco-américain. Il constate que « Les Franco-Américains établissent souvent eux-mêmes ce qui équivaut à un test de classement pour déterminer si quelqu'un a été élevé dans un contexte où l'on parlait français ou s'il a fréquenté une école paroissiale. Si vous ne correspondez pas à un de ces critères, vous êtes éliminé et l'on vous dénonce comme étant " seulement américain "》. Cette question de stéréotype m'a été posée plusieurs fois surtout par Madeleine Giguère de Lewiston. Peut-on être Franco-Américain et ne pas parler le français ? Il y en a qui diront non et d'autres hésiteront. Moi, j'ai toujours dit oui puisque l'identité franco-américaine ne se limite pas à la langue et à la culture, car, comme le dit Rodrigue, "Cette catégorie très limitée est devenue un stéréotype borné ». Il ne faut jamais dépendre des critères des autres pour déterminer sa propre identité. Mais il y en a qui tranchent l'affaire en blanc et noir pour mettre de côté tout ce qui n'est pas conforme à leur point de vue. C'est pour cela que j'aime bien le témoignage de cet auteur qui nous raconte l'histoire d'un Franco-Américain oublié, Tom Plant, du Maine. Et je suis d'accord avec Rodrigue que le « Maine, comme partie de la Nouvelle-Angleterre, [...] a également été négligé dans les études, même si cet État a été le lieu de plusieurs vagues de migration et compte, en nombre relatif, la plus importante population d'origine française, canadiennefrançaise ou acadienne des États-Unis ».

En ce qui concerne le témoignage d'André Gladu, je trouve que ce Québécois crève l'abcès du mépris en posant la question suivante : «Comment avais-je pu aller à l'école toutes ces années-là sans qu'on ne me parle jamais de la présence des Acadiens, des Cadjins, des Métis et d'autres francophones ?» Est-ce que le Québec se refermerait sur lui-même de plus en plus et 
oublierait ses cousins francophones et la culture populaire ? osé-je m'interroger même aujourd'hui. J'applaudis vivement André Gladu lorsqu'il dit : « Je trouve magnifique cette idée d'agir localement et de penser globalement ». Pour lui, c'est une question d'appartenir à une diversité et un " écosystème que constituent les cultures humaines ".

Le témoignage de Jean Morisset m'a beaucoup impressionné par sa franchise et par des questions qui s'allient avec les grandes lignes du témoignage de Barry Rodrigue. S'identifier avec ce que nous sommes est vraiment la question centrale ici. Morisset pose la question d'identité de la même manière que plusieurs d'entre nous nous la posons : « Mais, je sais pertinemment que je ne suis pas "French ", ni Français, mais quelque chose d'entièrement autre. J'aime bien le mot " Franco ", par ailleurs, il suggère plein de virtualités ». Il nous parle de Will James, de Jack Kérouac, Florence Rose Martin de Lewiston, Maine, et d'autres Franco-Américains non stéréotypés tel Alfred Poulin, mon ancien professeur d'anglais et de poésie au collège Saint-François à Biddeford. Le poète qui était originaire de Lisbon, Maine, a écrit des vers très puissants et même fulgurants à propos de la capacité de la reproduction des Franco-Américains et de leurs ancêtres. J'ai toujours cru que Poulin était fait du même moule que James Joyce ; il voulait voler au-delà de ses filets ethniques. Pourquoi ? Comme moi-même j'ai voulu le faire puisqu'il me semblait que le succès que nous poursuivions, nous, les rejetons d'une culture très éloignée de la source, se situaient dans des milieux yankees assimilateurs. Je remercie Jean Morisset d'avoir soulevé des questions auxquelles je pensais, mais que je ne voulais pas poser ouvertement par peur de mépris culturel.

En fin de compte, il y a le témoignage d'Éric Waddell qui lui nous parle " d'un univers tissé serré » où on « a tendance à exclure les déviants et les infidèles ». C'est un univers qui préconise " une stratégie de survivance et prôn[e] exclusivement la défense de la langue et la culture françaises, et la promotion de la foi catholique ». Il me semble que la question d'identité, de survivance et d'acceptation de la vie actuelle est toujours là pour nous défier et ne jamais être résolue. C'est là le problème de la Franco-Amérique à mon avis. Il n'y aura peut-être jamais de consensus en fait d'identité, mais le défi de remettre en question ce problème sera toujours, quant à moi, un défi fort intéressant, car il y aura autant de témoignages qu'il y aura d'individus, tels les auteurs des témoignages de Vision et visages de la Franco-Amérique.

Normand Beaupré

Professeur émérite Université de la Nouvelle-Angleterre, Biddeford (Maine) 